\title{
Educación, filosofía y libertad humana. Trazos pedagógicos a partir de Nietzsche, Freire y Zuleta
}

\author{
[Versión en Español] \\ Education, Philosophy and Human Freedom. Pedagogical Strokes \\ From Nietzsche, Freire and Zuleta
}

Educação, filosofia e liberdade humana. Traços pedagógicos de Nietzsche, Freire e Zuleta

Recibido mayo 20 de 2019. Aceptado septiembre 23 de 2019.

\author{
Yesid Niño-Arteaga* \\ https://orcid.org/0000-0002-5628-8854
}

Colombia

Para citar este artículo:

Niño-Arteaga, Yesid. (2020).

Educación, filosofía y libertad

humana. Trazos pedagógicos a

partir de Nietzsche,

Freire y Zuleta.

Ánfora, 27(48), 169-194. DOI:

https://doi.org/10.30854/anf.v27.n48.2020.673

Universidad Autónoma de

Manizales. ISSN 0121-6538 /

e-ISSN 2248-6941

\section{Resumen}

Objetivo: este artículo de Reflexión examina la relación de los filósofos Friedrich Nietzsche, Paulo Freire y Estanislao Zuleta en cuanto a sus posturas sobre la interacción entre educación, filosofía y libertad humana.

Metodología: se aplicó un enfoque crítico-filosófico, que permitió elaborar una reflexión interpretativa y crítica sobre el objeto de estudio. Para ello, se examinó parte de la literatura, ideas y planteamientos de estos tres pensadores que coinciden en la posibilidad de expresar el problema de la educación como liberación. Con base en los argumentos y posturas teóricas claramente identificadas en estos pensadores, emergieron las valoraciones e interpretaciones del presente trabajo; es decir, una interpretación crítica que se sustenta en lo planteado en esta tríada teórica. Resultados: para los tres autores la educación y su relación con la libertad humana implica la permanente apertura hacia la actitud crítica, la construcción-

\footnotetext{
* Magíster en Etnoliteratura. Licenciado en Filosofía y Letras. Estudiante de Doctorado en Ciencias de la Educación, Red de Universidades Estatales de Colombia. Docente de la Universidad de Nariño, Colombia. Integrante del grupo de investigación HISED. Correo: yesidnio@hotmail.com
} 
transformación y el arranque ético-político hacia otras relaciones humanas con los saberes y los valores (Nietzsche); persistir en la lucha contra todo tipo de opresión y la invisibilización de la alternatividad (Freire); encontrar en la educación filosófica, desde el reconocimiento del Otro y el desarrollo de pensamiento crítico, una posible fuente para lograr la afirmación de la vida (Zuleta). Conclusiones: la libertad en educación es saber con el fin de disentir, elegir, co-crear junto al Otro, para lograr un modo de ser y estar más inquietante; una actitud que permita sentir o desprender pensamiento sobre la sociedad, para comprender qué información, métodos, relatos se consumen, aceptan y transgreden y aprender a criticarlos y a criticarse, quizás apuntando hacia otra ética y hacia otras formas de pensar.

Palabras-clave: Filosofíadelaeducación; Críticacultural; Pedagogíalatinoamericana.

\section{Abstract}

Objective: this Reflection article examines the relationship of philosophers Friedrich Nietzsche, Paulo Freire and Estanislao Zuleta regarding their positions on the interaction among education, philosophy and human freedom. Methodology: a critical-philosophical approach was applied, which allowed for an interpretative and critical reflection on the object of study. For this, part of the literature, ideas and approaches of these three thinkers were examined, who all agree on the possibility of expressing the problem of education as liberation. Based on the theoretical arguments and positions clearly identified in these thinkers, the valuations and interpretations of the present work emerged; that is, a critical interpretation pertaining to what is stated in this theoretical triad. Results: for the three authors, education and its relation to human freedom implies the permanent openness towards the critical attitude, the construction-transformation and the ethical-political start towards other human relations with knowledge and values. According to (Nietzsche) education persists in the fight against all kinds of oppression and the invisibility of alternativeness (Freire). We find in philosophical education, the recognition of the Other and the development of critical thinking, a possible source of life affirmation (Zuleta). Conclusions: freedom in education is knowing in order to be able to dissent, choose, co-create with the Other, to achieve a way of being and cause more disturbance; having an attitude that allows us to feel or voice our opinions about society, to understand which information, methods, stories are consumed, accepted and transgressed and learn to criticize and criticize them, perhaps pointing to other ethical frameworks and other ways of thinking.

Keywords: Philosophy of education; Cultural criticism; Latin American pedagogy. 


\section{Resumo}

Objetivo: este artigo de Reflexão examina a relação dos filósofos Friedrich Nietzsche, Paulo Freire e Estanislao Zuleta sobre suas posições sobre a interação entre educação, filosofia e liberdade humana. Metodologia: foi aplicada uma abordagem crítico-filosófica, que permitiu uma reflexão interpretativa e crítica sobre o objeto de estudo. Para isso, parte da literatura, ideias e abordagens desses três pensadores foram examinadas as quais coincidem na possibilidade de expressar o problema da educação como libertação. Com base nos argumentos e posições teóricas claramente identificadas nesses pensadores, emergiram as avaliações e interpretações do presente trabalho; isto é, uma interpretação crítica baseada no que é afirmado nesta tríade teórica. Resultados: para os três autores, a educação e sua relação com a liberdade humana implicam a abertura permanente à atitude crítica, a construçãotransformação e o começo ético-político em relação a outras relações humanas com conhecimentos e valores (Nietzsche); persistir na luta contra todos os tipos de opressão e a invisibilidade da alternatividade (Freire); encontrar na educação filosófica, a partir do reconhecimento do Outro e do desenvolvimento do pensamento crítico, uma possível fonte para alcançar a afirmação da vida (Zuleta). Conclusões: a liberdade na educação é saber para discordar, escolher, co-criar com o Outro, alcançar um modo de ser e ser mais perturbador; uma atitude que nos permite sentir ou deixar de pensar na sociedade, para entender quais informações, métodos, histórias são consumidas, aceitas e transgredidas e aprender a criticá-las e criticá-se, talvez apontando para outra ética e outras formas de pensar.

Palavras-chave: Filosofia da educação; Crítica cultural; Pedagogia latino-americana. 


\section{Introducción}

Aún se hace válido resaltar la correspondencia que ha tenido la filosofía y la educación del ser humano a lo largo de su historia. Desde Tales de Mileto, descrito por Aristóteles como el primer filósofo, ya se suscitaba la importancia de relacionarse con la realidad, no solo por medio de preguntas sino también por medio de actitudes que lograran desplegar investigación, capacidad crítica y desarrollo de pensamiento.

En el siglo VI a. C., con los pensadores comúnmente llamados presocráticos, se diseminó una apreciable concepción de lo que hoy puede denominarse como parte de una filosofía natural (Feyerabend, 2015); estos pensadores dieron paso a que en medio de una comprensión mítica del mundo se emprendiera el estudio del ser desde una mirada filosófica que implicaba una perspectiva tanto empírica como racional, en la que se irán constituyendo espacios directamente vinculados con la enseñanza. Posteriormente, la historia de Occidente hablará de "escuelas" como la pitagórica, la Academia platónica, el Liceo aristotélico, el Jardín de Epicuro o el Cinosargo de los cínicos, donde la aritmética, la música, la política y la actividad filosófica eran la parte fundamental en la construcción del conocimiento.

Antístenes, por ejemplo, impartía sus lecciones en las afueras de la polis, en medio de un camino encumbrado, apartado y polvoriento, cuya simplicidad simbolizaba también libertad y autonomía. En dicha periferia se ubicaba el Cinosargo o el sitio particular asociado a la posible enseñanza de la filosofía cínica. El Cinosargo fue construido en honor al perro que robaba la carne que se destinaba como ofrenda en el templo del poderoso Heracles (Onfray, 2002). En este espacio de enseñanza y aprendizaje "se encontraban los excluidos de la ciudadanía, aquellos a quienes el azar del nacimiento no había hecho dignos de tener acceso a los cargos cívicos" (Onfray, 2002, p. 37). De este modo, el contexto de la filosofía antigua propone un conjunto de "ejercicios espirituales" que tienen por objeto "producir transformaciones en la naturaleza del sujeto" procurando el mejoramiento, perfeccionamiento y la realización de uno mismo como parte de una vida auténtica (Onfray, 2002, p. 15).

Frente a lo anterior, cabe preguntar si dentro de los propósitos de esa filosofía antigua no se presenta la urgencia de desarrollar tanto la parte de logos y de mythos que acaece en lo humano (Gadamer, 1997) y, en este sentido, cesta forma de educación no propende por la transformación mental y espiritual que procura al ser humano una mejor forma de vivir? Liberándose del estado de desdicha y de la insoportable inquietud ¿no es acaso como se comprenden los destellos de la sabiduría y de la inquietante libertad? 
Con estos interrogantes el artículo presentará una versión razonable, desde un enfoque crítico-filosófico, sobre parte de la literatura, ideas y planteamientos de tres pensadores que se interrelacionan teóricamente en la posibilidad de expresar concepciones diversas sobre el problema de la educación como liberación: Friedrich Nietzsche, quien indaga en el fracaso del proyecto de educación propuesto por la filosofía de la Ilustración y que fue asumido por la sociedad europea desde un fondo teológico, cuyo efecto fue la extensión del nihilismo y la moral hegemónica. Paulo Freire, quien despliega una relevante crítica respecto a la idea de libertad propuesta por el sistema capitalista, que en lugar de liberar pretende afianzar el discurso de la colonización y la mercantilización que resulta en el gran antagonista de la pedagogía freireana y, quizás, de toda pedagogía. Y Estanislao Zuleta, quien reafirma la confianza en una educación filosófica como manifiesto de las relaciones presentes en la posibilidad de vivir-pensar- liberarse-amar que conciernen a la idea de una educación integral del ser humano.

\section{Filosofia y educación, compenetración en la historia}

Ahora bien, durante el medioevo empieza a consolidarse un pensamiento filosófico occidental así como los proto-modelos de una posible universalización de la educación del ser humano. Se crean las primeras universidades y, de igual manera, se fortalecen monasterios y abadías. Es en los siglos XVII y XVIII, con los avances de la física moderna y la filosofía de la Ilustración principalmente, que se suscita el carácter universal de la educación como derecho público al servicio de la sociedad bajo la dirección del Estado. Esta se postulaba como servicio público en cuanto se promovió su carácter de obligatoriedad, gratuidad y laicidad, a la vez que reivindicaba la lógica de la ciencia y el discurso ideológico y moral amparado en una democracia ideal como parte de su proceso formativo.

Para pensadores como Rousseau (1999), Condorcet (1993) y Kant (2015), por ejemplo, la educación era la forma clara y elemental de buscar y adquirir libertad. La racionalidad será entendida como característica de la naturaleza humana que aspira a la libertad, ya que por medio de la formación del ser racional es como la humanidad puede desarrollarse en la historia por medio de una actitud crítica y el logro de su propia autonomía (Kant, 2015). Aunque este proyecto educativo, que es fundado en una libertad aprendida desde lo racional, irónicamente se apoyó en las concepciones políticas de la época que buscaban el robustecimiento del Estado al mismo tiempo que fue extendiéndose la conciencia de una cultura universal ilustrada.

Algunos sucesos políticos del siglo XIX resultaron ambivalentes en lo que respecta a la educación del ser humano, más que aflictivos si reconocemos los 
rastros del impulso hacia la guerra que se adentró en la mayoría de proyectos sociales y que, a su vez, hizo surgir el alboroto del mercado (primero industrial, luego bancario) y el espantoso desacierto de las guerras civiles y mundiales, como elementos de un posible progreso que vale la pena poner en cuestión. Este inquietante orden social fue acogido por gran parte de los gobiernos del mundo: se adoptó el aparato teórico de la filosofía de la Ilustración y el credo religioso medieval pero desde un contexto socio-cultural casi en su totalidad dogmático y reaccionario (Santos, 2014). Es más, si en el siglo XIX la educación humana se sostuvo hacia un aparente progreso en relación con el mundo y con el Otro, ¿parece desafortunado aspirar a la búsqueda de libertad identificando lo humano solamente desde un plano científico-matemático que procura adaptación y no transformación?

Por eso, ¿de qué idea de libertad se habla en el proyecto educativo de la Ilustración y cómo fue asumido por la sociedad europea? ¿Qué objetivos fueron propuestos por los proyectos educativos de Latinoamérica frente a los contenidos y valores que estaban atendiendo? ¿Qué puede decir la filosofía acerca de la libertad humana y su relación con la educación? ¿Libertad política, libertad de pensamiento, libertad civil, libertad de culto, libertad de expresión, libertad sexual? ¿Desde dónde se puede establecer una crítica al discurso de la libertad en la educación? ¿Es posible que se aborde críticamente el designio educativo que infiere la libertad basada solamente en el aumento de conocimiento? y ¿por qué en la actualidad esa idea de libertad ronda en la obsolescencia a pesar de que fundamenta gran parte de los propósitos de la formación escolar?

Estas interrogantes orientan el análisis y la crítica frente a las prácticas discursivas que refuerzan la moral hegemónica a las formas de pensar y actuar de los seres humanos en pro de extender el control y la coerción como formas de respaldo ante la idea de normalidad requerida por las estructuras de poder (Chomsky, 2001). Ante eso, cabe resaltar que la actividad filosófica concibe la educación como elemento clave o esencial en la relación con la búsqueda de libertad que impregna el devenir de los seres humanos. Comprender críticamente el tiempo de la educación y de la pedagogía en relación con la oportunidad filosófica puede permitir el desarrollo continuo de pensamiento crítico, liberador y transformador del pensamiento.

\section{Metodología}

Este estudio sigue un método basado en un enfoque crítico-filosófico, que permitió elaborar una reflexión interpretativa y crítica sobre la relación de Friedrich Nietzsche, Paulo Freire y Estanislao Zuleta frente a la interacción entre 
filosofía, educación y libertad. Para ello, se examinó parte de la literatura, ideas y planteamientos de estos tres pensadores que se interrelacionan teóricamente en la posibilidad de expresar distintas concepciones sobre el problema de la educación como liberación.

Con base en los argumentos Con base en los argumentos y posturas teóricas claramente identificadas en el material objeto de estudio, emergieron las valoraciones e interpretaciones del presente trabajo; es decir, una interpretación crítica que se sustenta en lo planteado en esta tríada teórica.

\section{Resultados}

\section{Nietzsche: Aurora y la crítica al proyecto de una educación ilustrada}

Tanto Nietzsche como Kant comparten la idea de que la educación tiene que ser el germen del desarrollo humano, de la construcción y transmisión de la cultura. Pero en cuanto a su desarrollo, Nietzsche se aparta de la luminosidad kantiana, Aufklärung, en cuanto la introducción del ser humano únicamente en el campo del saber científico. En desacuerdo con la búsqueda de un posible orden moral formulado por el imperativo categórico kantiano y su aspiración a la universalidad, la idea de educación en Nietzsche busca desestabilizar el orden cultural por medio de otra concepción de las prácticas de libertad y de las relaciones con los saberes.

Por lo anterior, en Morgenröthe, Nietzsche simboliza una posibilidad de transformación concreta, aurora o nuevo amanecer en cuanto a la constante indagación de los valores morales que, a su vez, implican una crítica al tejido pedagógico y filosófico de la Ilustración, cuya preeminencia amparada en criterios de utilidad, obediencia y cientificidad es concebida por Nietzsche (2000) desde la decadencia de las relaciones de lo humano con la naturaleza, puesto que se tiende a favorecer la asimilación de ciertas relaciones de fuerza que resultan convenientes a ese tejido cultural que es tan criticado por el filósofo alemán.

Aurora. Reflexiones sobre los prejuicios morales, puede verse como una propuesta por la afirmación de la pluralidad y por la incesante transvaloración (Nietzsche, 2003), que Nietzsche presenta como posibilidad de los "hombres de la conciencia" (Nietzsche, 2009), y no solo como una vehemente controversia a los valores morales de la época. Allí se fortalece el posible proyecto de transformación y crítica hacia el presente que Nietzsche acuña en torno a la educación.

Así pues, Nietzsche observa el nihilismo europeo y su moral decadente como resultantes del proyecto de la Ilustración asumida desde una forma de pensar 
generalizada en la que se advierte que lo humano todavía se encuentra sumergido en el tapiz de una ideología y una teología que también parece convenirle al saber científico (Nietzsche, 2009). La racionalidad es ahora racionalización, es decir, "la organización metódica de la vida y el sometimiento de la conducta humana a un conjunto específico de reglas con el fin de obtener unos resultados esperados" (Castro-Gómez, 2016, p. 53).

Según Foucault (2008), la educación -y no solamente la educación ilustrada, de la que quizá Kant es la figura más representativa en tanto su vertiente filosófica-, se puede definir como un proyecto de transformación y crítica hacia el presente, donde se trata de otorgar de habilidades y saberes a los sujetos por medio de la transmisión de conocimiento y, al mismo tiempo, se trata de modificar el modo de ser y estar de los sujetos (Foucault, 2008).

Al respecto, Gadamer (1997) habló de una primera Ilustración que irónicamente tuvo su apogeo con la extensión del cristianismo y su reducción de los mitos paganos y luego una segunda Ilustración que se dio principalmente desde el siglo XVIII. En ambas eventualidades el semblante y el ejercicio de esa ideología teológica (forma de conocimiento que se estampa en la plataforma de las relaciones sociales donde lo humano se suspende en el supuesto de una suprema finalidad que es provista por el estadio religioso), Nietzsche lo identifica directamente con la educación de su época, nutrida en lo mental por la filosofía Ilustrada, pero dosificada en el cuerpo por la trama del remordimiento judeocristiano y del sentimiento de codicia y su débil superstición de un más allá sin humanidad, es decir, sin vida (Nietzsche, 2009).

Es así que en el treceavo aforismo de Aurora, "Para la nueva educación del género humano”, se contempla una posible concreción pedagógica: la terrible consecuencia en lo humano que implica las prácticas de castigo. Y Nietzsche advierte la fórmula perversa con la que se usa este concepto, puesto que causa y efecto ha pasado a convertirse en "causa y castigo" (Nietzsche, 2009, p. 26). Esto significa la invasión de elementos de castigo, no sólo en el ámbito de la educación, sino en todos los ámbitos de la vida, lo que ha despojado a los posibles acontecimientos de su inocencia obligando al ser humano a sentir su propia existen-

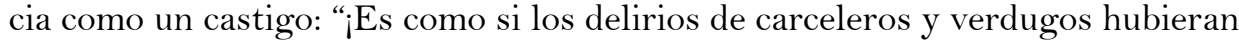
dirigido hasta ahora la educación del género humano!” (Nietzsche, 2009, p. 27). En el periodo Ilustrado la educación humana basada en la transmisión del conocimiento científico y en la adopción de la técnica se posiciona como algo universal que puede perpetuar el orden o el equilibrio del sistema social, haciendo del conocimiento eurocéntrico la esencia que logra determinar la relación con los saberes y en esta estación de ideas se encuentran precisamente los docentes, estudiantes y demás actores del proceso educativo (Santos, 2014; Kincheloe, 2001). 
Lo humano, para Nietzsche, no se separa de la razón, pero la razón es para Nietzsche simbolización y experiencia de la diferencia. "Hombre" significa "pensador": ahí se esconde la locura" (Colli y Montinari, 2004, p. 32). Nietzsche desconfía de la supuesta "gran claridad" del conocimiento científico; en su filosofía la avenencia lógica se rige por el principio de contradicción como superficie de la diferencia (Colli y Montinari, 2004) y se admite que el intelecto se sostiene en formas fijas porque estas son inevitables dentro de la vida, pero eso no significa que sean consideradas como verdaderas simplemente porque se llega a estas por medio de un esfuerzo lógico. Nietzsche comprende que la persona es verdaderamente libre cuando se desenvuelve activa e íntimamente en el presente de su historia.

Hemos superado a los griegos en la dilucidación del mundo, por medio de la historia natural y la historia humana, y nuestros conocimientos son mucho más amplios, nuestros juicios más correctos y moderados. También se ha difundido un sentido edulcorado de «humanidad» [Menschlichkeit], propiciado por la Ilustración, que ha debilitado a los hombres -pero esa debilidad, metamorfoseada en moralidad, presenta un aspecto excelente y nos honra. El hombre tiene ahora mucha mayor libertad, cosa suya es que la use tan poco; el fanatismo de la opinión está muy atenuado. Que en última instancia queramos vivir en esta época antes que en otra cualquiera, es esencialmente mérito de la ciencia, y no cabe duda de que para ninguna generación ha existido semejante suma de nobles gozos tanto como para la nuestra - aun cuando ésta no tenga ni estómago ni paladar para poder experimentar muchos de esos gozos - Mas con toda esa libertad, hoy se vive bien solo cuando uno se limita a comprender, sin querer tomar parte activa - éste es el inconveniente moderno. Quienes toman parte activa resultan menos atractivos que nunca. ¿Qué tontos deben ser! Surge así el peligro de que el saber se vengue de nosotros, tal como la ignorancia se vengó de nosotros durante la Edad Media (Colli y Montinari, 2008, pp. 61-62).

Por eso, el filósofo alemán contradice la dimensión crítica y ética de la proyección de sujeto y de humanidad que encareciera las inventivas de una cultura hegemónica. En este sentido, no son las políticas guerreristas, el fanatismo por el dogma judeocristiano o la piadosa aceptación de la mala conciencia simples metáforas de una crítica cultural anterior, sino que se encuentran vinculadas a la realidad educativa del presente, que identifica como proveniente de la filosofía de la Ilustración desarrollada en un contexto enteramente dogmático. El error, resalta Nietzsche a lo largo de Aurora, fue proponer a la educación humana en su conjunto como simple aparato para la configuración de sujetos dóciles con fines mercantilistas y utilitaristas. 
Sin embargo, como en muchos casos, en ciertos aspectos su propuesta resulta algo elitista. Recordemos por ejemplo que, al igual que Platón, Nietzsche también defendió un sistema social piramidal y la necesidad del trabajo siervo-esclavo para que una minoría selecta se pueda consagrar a la creación, al ocio, a la cultura y que al igual que Schopenhauer (2002) desconfía por completo de la democracia y de las ideologías, sin embargo, considera enfermiza y decadente la manera en cómo la cultura de su época se apropia del proyecto de educación propuesto por la filosofía ilustrada.

Ahora, la metáfora de "carceleros y verdugos" resulta en una subversión no solo al sistema educativo sino también al confort del pensamiento del docente, quienes para Nietzsche resultan también "sacerdotes" de la mala conciencia al no examinar críticamente su propio pensamiento y prefieren convertirse en diseñadores, transmisores y ejecutores de las teorías y prácticas de la domesticación de lo humano.

¿Qué es el sujeto domesticado? Pues quien se gratifica de obedecer con fidelidad antes que pensar con creatividad. Al contrario, la crítica pedagógica de Nietzsche es una apuesta ante la deficiente realidad subjetiva, afectiva y creativa que el filósofo observa en los seres humanos y en el sentido de humanidad, libertad, valores que se suministran por el resplandeciente y aparentemente vigoroso rumbo educativo.

¿Liberación? El filósofo alemán logra advertir de la opresión subjetiva y espiritual que implica este tipo de iluminismo aplicado y distribuido desde instituciones y sujetos autoritarios e indiferenciables. "Los pensamientos son signos de un juego y una lucha de afectos: siempre están en conexión con sus raíces ocultas" (Colli y Montinari, 2004, p. 148). No es solamente una crítica a la forma de pensar que logra imponerse desde la formación del sujeto, es también un intento por realizar una transvaloración de los aspectos supuestamente exclusivos o inamovibles de las relaciones de saber y de poder que están inmersas en el aparato de la educación, allí se distingue el sentido de esa liberación nietzscheana.

Resulta, entonces, un poco fácil apoyar la insistente tesis que concibe a la filosofía nietzscheana como una promesa encaminada a la devastación o la dominación, que se fundamenta en "la inerradicabilidad del odio, crueldad, impulsos tiránicos, en la lógica de la sujeción, la subordinación, etc.” (Siemens, 2014), pero desde otro entendimiento de su filosofía, empezando por su reinterpretación a partir de su obra póstuma que fue recogida críticamente por Colli y Montinari (2004, 2008); además, a través de los estudios realizados por Heidegger (2013), Deleuze (2013), Jaspers (2003), por ejemplo, se puede sostener que su filosofía "culmina en ideales afirmativos que excluyen la dominación y la devastación" (Siemens, 2014, p. 101), los cuales pueden proporcionar fundamentos a la alter- 
natividad y nuevos elementos para la constante apertura crítica de las ciencias humanas y sociales (Deleuze, 2013).

Bajo esta otra interpretación se puede decir que la filosofía nietzscheana no reniega del sapere aude kantiano que busca que el ser humano logre valerse de su propia razón para liberarse de los atributos e imposiciones externas, ya sean emanadas por sujetos que obedecen ciegamente al Estado, la Iglesia o a la misma escuela (Kant, 2015). En su característico llamamiento a la contradicción, Nietzsche aprende de Kant que facultades como la imaginación, el entendimiento y la razón se relacionan entre sí desde una posibilidad activa y no pasiva, aunque luego él las llegue a distinguir como arte y conocimiento (Nietzsche, 2009).

En este sentido, se busca una liberación del sí mismo en relación con la realización del Otro, una ipseidad radical para alcanzar la inconcebible alteridad. Es así que para Kant la realización del ser se alcanza en la crítica y esta debe manifestar un alto grado de concordancia entre las facultades (imaginación, entendimiento y razón) así como la justificación del génesis del sentido común (Deleuze, 2008, p. 46).

Contundente pero sin desvincularse del sapere aude kantiano: "somos hombres de la conciencia: no queremos volver a lo que nos parece trasnochado y apolillado, a algo 'inverosímil', ya se llame Dios, Virtud, Verdad, Justicia, Amor al prójimo; que no nos permitimos puentes de mentiras a viejos ideales" (Nietzsche, 2009, p. 16). Nietzsche tiene que mantenerse en el plano de lo ininteligible debido a que esa es la gran certeza que enseña la filosofía de Kant (Nietzsche, 2009, pp. 143-144). Pero Nietzsche difiere de Kant en tanto este último, al igual que los filósofos idealistas, invoca un principio teológico para tratar de responder a cualquier experiencia que exceda los límites de la racionalidad (Deleuze, 2008), situación que Nietzsche indica por medio de la distancia esencial, ni bien ni mal, ni amor ni odio: esa es la antigua fortaleza.

En este punto, es menester conocer que si hay lugar para un transitar, para un "puente", según Nietzsche, este no puede ser otro sino el advenimiento de lo humano metaforizado como Übermensch que es la metáfora que logra la disolución de "los majestuosos edificios morales" que son representativos de la doctrina kantiana (Nietzsche, 2009, p. 14). Por eso, la filosofía nietzscheana resalta románticamente que se aprende a leer y escribir jugándose la vida; filosofía y demolición de los dogmas; liberarse mediante el inclemente momento de pensar. ¿Acaso hay otra forma de metamorfosear las relaciones de fuerza, activas, creadoras, que no sea la atenta lectura y la escritura desde la diferencia como intermitencias de un posible acontecimiento?

Nietzsche también arremete contra la idea de una libertad humana fundada en la lógica del mercado o en su supuesta primacía ético-ontológica; es un crítico de la mercantilización de las relaciones humanas y de la nueva y aparente 
libertad condicionada por la dimensión de precio o de deuda que sean capaces de generar los individuos de una sociedad. Es un error que las relaciones humanas sean determinadas por las leyes del mercado (Nietzsche, 2009, pp. 165-167).

Así mismo se enfrenta, teóricamente, a las formas de ser que operan bajo los términos de seguridad (sentimiento se seguridad, seguridad colectiva) o bajo leyes morales supremas que son impuestas por las "tiranías del miedo" (Nietzsche, 2009, p. 166). En Aurora los aforismos 174 y 175 se dirigen exclusivamente a analizar la decadencia social y la mala conciencia que arrojan las "afecciones simpáticas" de la mercantilización de lo humano (proporcionar exceso confort y continuo bienestar al otro como el perfecto disfraz del impulso social del miedo).

Afirma (Nietzsche, 2009) que "Vemos surgir actualmente la cultura de una sociedad para la cual el comercio es el alma” (p. 167). Es decir, Nietzsche desconfía de la lógica mercantilista que parece apropiarse de todos los aspectos del conocimiento humano: “¿quién y cuántos consumen esto?” (Colli y Montinari, 2004, p. 167), ya sean las artes, las ciencias, las religiones, la educación humana, la política, los pueblos, los partidos Una cultura que basa su destino en la mercantilización de la realidad y en la explotación de la naturaleza, que desprecia las dificultades y la complejidad de lo humano, implica, según Nietzsche, que todo lo que se produce se dilucide e interconecte por medio del discurso de la oferta y la demanda.

Aunque cualquier proyecto o movimiento político emancipador le parecía a Nietzsche dominado por la "moral de esclavos", se debe mencionar que su idea de "liberación” se afirma desde una experiencia estética individualista. Es por eso que para Nietzsche el trabajo del pensamiento es lo que le permite al ser humano moverse en el terreno pluralista del ser y del conocer, por medio de la posibilidad de la transvaloración y la creación como elementos indispensables para la afirmación de la vida.

Nietzsche llama voluntad de dominio a una fuerza unificadora, perfectamente impersonal, que confiere una nueva ordenación y una nueva interpretación a elementos que estaban hasta entonces determinados por otra dominación. Esta noción es por lo tanto, no solo ajena a la significación que le asigna la ideología dominante, sino directamente opuesta, ya que en esta última voluntad de dominio se entiende como el deseo de dominar, superar, oprimir a otros, someterlos a los valores y jerarquías existentes (Zuleta, 2018, p. 146).

La condición de multiplicidad logra imprimir varios sentidos en la realidad de las cosas: no hay un solo lenguaje, no hay un camino recto e inequívoco en el conocimiento, tampoco el designio u objetivo de una aspiración a lo absoluto, puesto que es por medio de la condición de multiplicidad que se puede asediar 
los sentidos así como las conceptualizaciones de los saberes. De esta forma, el individuo se libera bajo la tutela de la transvaloración que implica la voluntad creadora y el vivir de la manera más humana posible.

Por lo anterior, las indagaciones sobre lo humano no concluyen en la filosofía nietzscheana y se proponen como inminentes en cuanto al sentido de libertad, el cultivo del gusto y de una manera de pensar que manifieste la diferencia frente al utilitarismo e igualitarismo de las preponderantes compensaciones de la racionalidad científica o de una religión que difícilmente se asume como inequívoca (Deleuze, 2013, p. 67). Al respecto, Nietzsche señala que la ciencia "es el intento de crear para todos los fenómenos un lenguaje convenido y común con el fin de hace a la naturaleza más fácilmente calculable, y por ende, dominable" (Colli y Montinari, 2004, p. 113).

Por eso, la filosofía nietzscheana asume la liberación desde la transvaloración como posibilidad de contradicción frente a elementos de la "mala conciencia" como los planos de identidad, igualdad y equilibrio solidificados en una forma de pensar rígido-matematizable y teológica-utilitaria que no permite afirmar la diferencia o la multiplicidad de sentidos y que más bien presentan la realidad humana como algo uniforme e indiferenciado (Deleuze, 2013). Para Nietzsche si el estadio racional opera en la indiferencia su proyecto también termina abruptamente en una disposición sin lugar a las diferencias, operación bajo la dimensión ascética y religiosa de la moral dominante que en una posible síntesis nietzscheana se entiende como una prejuiciosa e insuficiente descripción de lo que acontece.

\section{Freire y la realidad del oprimido: colonialidad y racismo en Latinoamérica}

Si Nietzsche advierte del posible peligro de la mercantilización de lo humano, casi un siglo después, en Latinoamérica, Paulo Freire se enfrenta, desde la pedagogía y la filosofía de la educación, a un segmento del problema que el filósofo alemán había ya descrito en gran parte de su obra. Nietzsche realiza una crítica a la forma en que se asumió el proyecto de educación humana propuesto por la Ilustración y al respecto Freire denuncia que este modelo racionalista fue adecuándose en América Latina por gran parte de los gobiernos y por las élites políticas y académicas. Este prototipo de educación arribó en el contexto suramericano instaurando, a la vez, una especie de afianzamiento molecular de los problemas del colonialismo, la mercantilización y el afán de desarrollo desde lo monetario dieron paso al fortalecimiento del racismo en los cuerpos como en las subjetividades. 
El problema del colonialismo, según Dussel (2016), inicia con la conquista de los océanos Pacífico y Atlántico por los europeos; españoles, portugueses e ingleses, principalmente, fueron organizando un mundo colonial del siglo XV al XVIII en los territorios americanos. Dicho orden mundial, al mismo tiempo, propone elementos filosóficos, políticos, religiosos y lingüísticos extraídos de la cultura "latino-medieval" que, sin duda, se arman bajo la pretensión de universalidad de una "filosofía moderna europea" estableciendo al mismo tiempo una instancia de dominación y hegemonía sobre las formas de pensar de las comunidades-otras (Dussel, 2016).

Sin embargo, el inconveniente de una filosofía con aspiraciones a conformar universales es que resulta en una adhesión por aplicar relaciones hegemónicas a las otras formas de pensamiento filosófico o no. Por eso, el problema tiende a llamarse colonialismo y colonialidad, porque no fue solo el establecimiento de colonias europeas por medio de la violencia directa y la guerra; también se rata de la herencia que aún permea dentro de las subjetividades, de las formas de pensar y de relacionarse con el Otro y con la Naturaleza.

El colonialismo basado en un "eurocentrismo filosófico" es puesto en cuestión por Dussel (2016), Santos (2014), Castro-Gómez (2016), Mignolo (2017) y Freire (2002, 2015), entre otros pensadores, que coinciden en que este proceso de dominio se apoyó en una filosofía particular con pretensiones de establecer universales, que acabó por destruir e invisibilizar los recursos teóricos de las demás culturas (Dussel, 2016, p. 22).

Por su parte, para el filósofo colombiano Santiago Castro-Gómez el colonialismo que se levantó en las Américas desde el siglo XVI "fue la base sobre la cual se asentó la división racional e internacional del trabajo que daría impulso a la expansión del capitalismo por todo el planeta” (Castro-Gómez, 2016, p. 53). Cabe resaltar que colonialismo "hace referencia al sometimiento militar, ocupación territorial, y administración jurídica de un pueblo por parte de una potencia imperial extranjera” (Castro-Gómez, 2016, p. 260); además, el colonialismo arrastra consigo otro episodio desafortunado llamado colonialidad, que "alude a las herencias que el colonialismo deja en el orden simbólico, afectivo y cognitivo" (Castro-Gómez, 2016, p. 260).

En la colonialidad, según Mignolo (2017), subyace el lado más oscuro de la modernidad: el racismo, la explotación, la desposesión, la reducción de lenguas, la depreciación de otros saberes. Según Mignolo (2017) la permanencia en un “punto de vista epistémico hegemónico" (p. 406) es el marco de referencia de la colonialidad. Frente a ese problema, el pedagogo Paulo Freire valora a la actividad educativa como el hecho inaplazable para reconstituir la indagación sobre lo humano y lo social que parece olvidarse o confundirse con contenidos y propósitos deslocalizados o descontextualizados propios del colonialismo. 
Para este pedagogo, entonces, la educación es lo que hace al ser humano capaz de ascender de la ingenuidad al criticismo, es decir, lo que le permite trazar la búsqueda de su libertad (Freire, 2002). Para Freire la colonización "fue ante todo una empresa comercial” (Freire, 2002, p. 61), una explotación económica de los recursos naturales y un enfrentamiento violento con las culturas nativas bajo el interés de extender la explotación comercial de la tierra.

En la pedagogía freireana la educación se propone como proceso humano en atenta vinculación con el Otro y que se realiza para ejercer el cambio social y para afianzar la libertad individual. La elección de toda época está entre participar de una educación para la domesticación alienada o de una educación para la libertad (Freire, 2002, pp. 25-26). En este punto la educación para Freire será la apuesta por la liberación de los sujetos de los preceptos de la colonialidad.

A lo largo de su obra Freire sustenta la posibilidad de ejercer total radicalidad en la transformación de los órdenes afectivo, cognitivo y simbólico. Manifiesta que la opresión también ocurre por la mercantilización de las relaciones humanas, por el sometimiento del pensar al campo de la violencia y el miedo. En este sentido, si la educación es trasmisión del conocimiento, transformación de los saberes y construcción de valores humanos y mutación de la cultura, también debe ser el sustrato donde se afirme la eventualidad de la crítica y la re-creación de otras relaciones.

Por mercantilización de lo humano puede entenderse el criterio de explotación que opera en torno a la consecución de fines lucrativos para las relaciones humanas. No solo se explota al sujeto en sus realidades laborales, también se explota al sujeto en sus condiciones vitales: se explota su libertad, sus sueños, su conciencia, su psiquismo (Han, 2015). La mercantilización de lo humano puede ser tratada como problema que toca lo educativo, debido a que en esta contrariedad el advenimiento de la sociedad radica no en su humanización sino en su cosificación.

Y con Freire la educación no tiene otro posible propósito sino la humanización del ser humano, superar la ingenuidad y alcanzar la actitud crítica frente a: 1) el afán de extender el ideal de mantener la explotación comercial de la tierra para beneficios de minorías oligarcas (ser parte activa de la colonialidad), y 2) los proyectos pedagógicos que son referencia en la formación de sujetos dóciles y, sobre todo, que sean útiles al anterior punto. En ese tipo de "educación bancaria", como la llamó Freire, el ser humano no puede comprender su situación histórica, social o política y frente a la tecnologización de las relaciones humanas tiende a no interesarse por las problemáticas humanas ni por la situación del mundo o se encuentra por fuera del gusto y la "necesidad de saber" (Freire, 2015, p. 95).

La crítica de Freire al sistema capitalista radica en la operatividad política y económica de este tipo de educación bancaria, formar consensos y también suje- 
tos para supuestamente corresponder al proyecto informático y globalizante del siglo XXI, pero no suministra conocimientos ni valores para que el ser humano se enfrente a los innumerables problemas sociales que también se pueden inferir en dicho proyecto.

Por ejemplo, el problema del racismo, que según Wallerstein (2005) es parte funcional de la economía-mundo capitalista, y por tanto, se ha difundido considerablemente, pero su debate y su crítica se ha hecho menos visible en lo público (Wallerstein, 2005). Este problema es político y económico puesto que todavía se sostienen propósitos como: i) mantener a la gente dentro del sistema como seres inferiores a quienes se puede "explotar económicamente y usar como chivos expiatorios” (Wallerstein, 2005, pp. 66).; ii) participar de la actitud acrítica que permite el crecimiento del individualismo y la extensión de las desigualdades sociales históricas; iii) acrecentar la base en la que gira una supuesta superioridad e inferioridad cultural y de allí la justificación de intervenciones políticas y/o militares.

Tanto Freire (2015) como Wallerstein (2005) entienden que esta economía capitalista, con la vigencia del neoliberalismo, justifica sus jerarquías sobre la base de problemas económicos y políticos como el racismo (Wallerstein, 2005) y desde otras formas de expresión discriminatorias, como el sexismo, el machismo, el clasismo y la "violencia verbal" (Freire, 2015, p. 141), que también hacen parte de la lógica colonialista-capitalista. De allí que la pedagogía freireana busque la liberación del ser humano a través de la lucha contra cualquier forma de opresión económica y política; por eso, en Freire la educación humana resulta en un acto eminentemente político.

En Freire se expresa una clara relación entre educación y cultura política: una práctica político-pedagógica (Freire, 1980, 2002, 2015); y se hace pública la tesis de que la educación no puede ser apolítica, puesto que se hace cada vez más difícil de sostener que en la educación humana no se despliegue el compromiso, la intermitencia o la duración de lo político; sostener esta opinión resulta para Freire en una falacia que conviene al esquema capitalista. En la pedagogía freireana la práctica educativa no tiene que fundarse en la estandarización ni en la rutina de lo preestablecido, ya que eso significaría asimilar el proyecto de adaptación del neoliberalismo que gira en la burocratización y en el fantasma de una democracia que más bien resulta en una anti-democracia (Freire y Faundez, 2018).

Entonces, para Freire la práctica educativa y el discurso pedagógico sobre la educación humana aún se desenvuelven en la posibilidad de creatividad. Una liberación que inicia en la lucha contra la opresión de las subjetividades; en darse cuenta que también se dan formas de opresión en la educación actual y estas no se hacen de manera directa o física, sino que se establecen sobre un principio de positividad que se maximiza en la psique humana a través de la desorientación 
en el mundo del hiperconsumo y del reduccionismo propio del discurso de la oferta y la demanda.

Quizás con Freire también se logre advertir que, dentro de una sociedad en extremo capitalista, la opresión se asimila y se ejecuta desde distintas formas. La creciente “introyección de la dominación” (Freire, 2015, p. 56), que resulta contraria a la problematización de la cultura de la dominación, busca aprisionar a los sujetos en un tiempo determinado en el que no se busca ninguna forma de lucha. Por ejemplo, siguiendo al filósofo Byung Chul Han, en la actualidad esto puede evidenciarse en la aplastante tecnologización de los cuerpos que se hace dentro del "desnudamiento voluntario" por medio del uso acrítico del smartphone u otros aparatos "inteligentes" (como representación del consumismo de lo tecnológico); además, por medio de la sobre-exposición en espacios virtuales donde prima el perpetuo intercambio y el exceso de información, que vienen a presentarse como la forma de opresión, tortura y vigilancia más eficiente (Han, 2015).

Con Freire se comprende que en el proceso educativo se debe superar toda concepción bancaria de la educación, en la que priman las relaciones verticales: un amo, un receptáculo y una serie de conocimientos para que el amo los dosifique según su voluntad. Para Freire la pedagogía es también una lucha contra la forma mecánica de someterse a los conocimientos heredados que intentan reproducir los valores socialmente dominantes. Frente a esto, con la pedagogía freireana se puede comprender que la idea de libertad en el ser humano no abandona su carácter de lucha, de riesgo, fulgor de la curiosidad, apertura a la pregunta y reconocimiento de la crítica, una dirección política hacia la alternatividad, un riesgo por la transformación de la cultura, a partir de la construcción de sujetos con personalidades libres, críticas y autónomas.

\section{Estanislao Zuleta: la educación filosófica frente al apogeo de la explotación y la guerra}

Para Estanislao Zuleta la educación es lucha, un “campo de combate” (Zuleta, 2016), que se acentúa en la producción y transformación del conocimiento que procura la ampliación de la actividad crítica y de la responsabilidad con el vivir y con el pensar. Zuleta vivió el violento siglo XX colombiano, mientras se alimentaba intelectualmente de la filosofía kantiana, nietzscheana y heideggeriana; aprehende elementos vitales y los enseña para que los sujetos puedan enfrentarse a los fenómenos sociales y humanos del presente. Por eso, con Zuleta la educación se entiende como liberación de la domesticación. Y frente a esto, el lenguaje filosófico de Zuleta es franco: parte de la tragedia colombiana es la educación para la uniformidad del sujeto, "la educación inhibitoria del pensamiento, el deseo y el saber. Una educación realizada para que los individuos no actúen, 
para que no sean sujetos de su historia, que es una manera de impedir, de controlar el pensar y el actuar” (Zuleta, 2016, p. 83).

La posibilidad que ofrece la crítica cultural de Estanislao Zuleta radica en que el pensamiento humano tiene todas las capacidades para deslindarse en gran parte de la memorización de la información, de la repetición del conocimiento y del alejamiento de la crítica, que son procesos muy ligados a la formación escolar y a la conciencia capitalista del presente (Zuleta, 2016). La domesticación en la educación inicia al creer que solo se trata de memorizar y repetir lo que al maestro-domesticado y al aparato educativo domesticador le conviene: encajar y corresponder a los propósitos del mercado y la industria tecnológica sin evocar pregunta alguna por el ser o la nada o por el bien y el mal o por la trascendencia y la inminencia y, quizá, aún menos por el presente o el porvenir.

${ }_{¿}$ Concurre o se extiende un alejamiento del ser humano de su capacidad crítica? Zuleta analiza el sistema educativo colombiano de finales del siglo XX y advierte que cada vez más se acrecienta el confort y el facilismo de asumir un conocimiento eurocéntrico puesto que se sostiene sobre aparentes verdades incontrovertibles y emparentadas a una formación escolar muchas veces acrítica o que deja de lado la necesaria “angustia de pensar” (Zuleta, 2016, p. 21). La educación está siendo configurada cada vez y de manera alarmante con los métodos, modelos y discursos de la industria y el mercado (Zuleta, 2016).

Esto lleva a Zuleta a establecer una crítica al pensamiento de los maestros y su transmisión a los estudiantes; señala, desde su contexto sociocultural, que los primeros tienen la posibilidad de desplegar la actividad de pensar por medio de una lucha intelectual contra el sistema que admite la domesticación, promoviendo en la gente no la adaptación a las formas de vida del mercado o del neoliberalismo financiero (comprar, vender, adeudar), sino la concepción de una mejor sociedad que logre defender el mundo de la vida, sin caer en el despotismo de inhibir el decir o reprimir el pensar. En el contexto escolar colombiano, indica el análisis de Zuleta (2016), es el estudiante quien parece no tener derecho a pensar, es decir, a criticar, a contraargumentar, a controvertir, a proponer, a crear, a trasformar y a vivir el conocimiento.

La crítica a la educación hecha por la filosofía zuletiana implica un recomienzo de la actitud crítica, no sólo en recordar o repetir lo que se puede extraer de un modelo de educación preestablecida por el monopolio de una monocultura neoliberal, sino también en entender críticamente los procesos de adquisición de conocimiento, intercambio simbólico e interconexión con el Otro, sin caer en la pasividad de una verdad dogmática carente de vida e interés investigativo.

¿Desarrollar el pensamiento crítico o inhibir el pensamiento crítico? Ante esa posible intencionalidad, Zuleta lanza una crítica filosófica al papel del maestro, al modelo educativo eurocéntrico, a los criterios de regulación del pensar y 
represión del cuerpo que ocurren en la escuela precisamente por la ausencia de filosofía en la formación escolar. Para Zuleta (2016) el gran error de la escuela es educar sin filosofía y bajo esa debilidad, la conformación sin interrupciones de un camino o pasaje que busca la adaptación y la domesticación de la existencia y con esto el perfecto desarrollo del modelo financiero.

Pero, ¿qué es filosofía y qué importancia tiene para la educación del ser humano? Para Zuleta, la filosofía "es la posibilidad de pensar las cosas, de hacer preguntas, de ver contradicciones” (Zuleta, 2016, p. 23), lo que le permite al ser humano la realización de su ser por medio del saber, "saber por qué hace algo, saber para qué lo hace, para quién lo hace” (Zuleta, 2016, p. 23). "La filosofía no es un cuerpo de saber que pueda ser transmitido. Es una práctica de la crítica. Es una sospecha organizada, exigente y rigurosa. Este tipo de actitud es la que tendríamos que tratar de enseñar" (Zuleta, 2016, p. 118).

Zuleta propone una perspectiva sobre la educación humana cuya base no se regule por las intenciones ni del sector financiero ni de la industria informática y audiovisual, puesto que en esta regulación monetaria y luego cibernética, que hace parte del proceso de domesticación, los sujetos tienden a preocuparse por la adquisición consecutiva de moneda, a adquirir mayor información con un mínimo de esfuerzo, es decir, se reproduce más no se piensa (Zuleta, 2016, pp. 19-25). La educación humana empieza a moverse en el mundo de la súper-producción aplicando sin inconveniente alguno la lógica del mercado (compra-venta, oferta-demanda, deuda-crédito), donde se confunde el educar al ser humano con accesos inmediatos a cúmulos de información mientras se provoca una ilusión de aprendizaje que se desenvuelve en una ideología del consumo.

Esta situación, sin duda alguna, puede considerarse como una problemática que en la actualidad puede denominarse como "capitalismo cognitivo" que, según Galcerán (2007), delimita la centralidad del modo de producción de la coyuntura capitalista en la producción del conocimiento de los sujetos. Y es que en relaciones en las que se asume el carácter capitalista sin ejercer dominación y/o explotación directa, los sujetos se desenvuelven en la ilusión de sociedades aparentemente libres, establecidas en la "libre" circulación de la información y en el "libre" flujo de las expresiones, pero que también tiende a reconfigurar el aparato educativo atendiendo a las cuantificaciones del mercado global (Galcerán, 2007).

Paradójicamente, es el avance del conocimiento humano dentro de un contexto donde generalmente priman la colonialidad, los dogmatismos o la hegemonía de una ideología del consumo, lo que promueve o genera una nueva forma de energía que logra invisibilizar la crisis del capitalismo.

Según Zuleta, la ausencia de filosofía en las escuelas (y en la vida del ser humano en general) desemboca en que el sujeto adopte una "ilusión de aprendizaje” (Zuleta, 2016, p. 22) que limita a ver, oír, repetir y reproducir antes que 
provocar o incitar la actividad-pensamiento. La filosofía de Estanislao Zuleta señala que quizás ese sea el aspecto más nocivo de una "tecnología educativa" sin actitud crítica, la represión del pensamiento, un alejamiento del concepto en la asimilación del conocimiento y la imposición de una "ilusión de aprendizaje" que se solidifica con la formación escolar incomunicada con la filosofía, entendida como una herramienta para la apropiación vital de los conceptos e indispensable para la autonomía y, al mismo tiempo, para la lucha por una sociedad conformada por personas que aspiran a la emancipación, a la racionalidad y a ser sujetos de su historia (Zuleta, 2016).

Zuleta asume la noción de educación filosófica desde un plano racionalista. El cultivo de la razón en conjunto con el desarrollo de pensamiento crítico es parte fundamental de esa liberación. Zuleta aprende de la filosofía kantiana que el racionalismo de la filosofía puede ser el armazón que sostenga un posible proyecto pedagógico racionalista (en una perspectiva no demasiado eurocéntrica) que pueda brindarle a la educación y a la formación escolar de los sujetos la capacidad de renunciar a una mentalidad pasiva que ya no acepta la autoridad, la tradición, las supuestas verdades o los prejuicios sin antes someterlos a la crítica; que les proporcione conocimientos y valores para comprender la realidad del Otro y así entrar en diálogo con otros saberes. Liberarse de la domesticación para ser conscientes del necesario riesgo de pensar que implica aceptar el error, la incompletud y la equivocidad como atributos de lo humano.

\section{Puntos de encuentro: educación, liberación, pensamiento crítico y alteridad}

En la filosofía nietzscheana se impulsa el sapere aude pero de manera radical, es decir en un plano de inmanencia y no de trascendencia. No se trata de una liberación de la naturaleza sino una liberación del estado cultural de lo necesario. Para Nietzsche un estado cultural nihilista y decadente sucede en tanto se suprime la misma búsqueda de la libertad sin haber comprendido la liberación como un derrame ininteligible que implica el desarrollo de fuerzas activas en las relaciones humanas. La imitación y veneración de la naturaleza son elementales al perspectivismo de la filosofía nietzscheana. Su comprensión instintiva radica en poder crecer con la naturaleza de manera íntima y sin someterla (Nietzsche, 2000).

El ser humano se educa para reconocerse en la naturaleza. Según Nietzsche, en la imperecedera lucha por la vida la educación hace y trasforma la cultura (Nietzsche, 2000). A propósito, Freire habla en este sentido de "mutación cultural" (Freire, 2015), de que la lucha cultural también es una lucha contra la 
opresión política y económica (Freire y Faundez, 2018). Tanto Nietzsche como Freire se oponen a la educación guiada por el determinismo de la lógica del mercado y del criterio de lo útil que aspira a reproducir formas de vida que simplemente sean combustible para el proyecto de domesticación acuñado tanto por el nihilismo como por el capitalismo.

De allí que exista en Zuleta una relación entre pensamiento crítico y filosofía como expresión-motor que puede transformar la realidad de las escuelas dentro su trabajo en la formación de sujetos que aspiran al saber: un campo de batalla abierto por la escritura y la investigación (Zuleta, 2018). "El trabajo de la sospecha consiste en someter todos los elementos a una elaboración y a una crítica, que permita superar el poder de la fuerza -represión, ideología dominante, racionalización, etc.- que los mantiene dispersos, yuxtapuestos o falsamente conectados" (Zuleta, 2018, p. 150). Una educación filosófica como alternativa a la domesticación propia de la educación bancaria y acrítica que aparta a las personas de su papel dentro de la historia como transformadores de la misma.

En este punto se puede destacar que tanto para Nietzsche, como para Freire y Zuleta, la educación es liberación: Befreiung, libertação, aspiración a la libertad del pensar. En primer lugar, liberación contra la opresión o el disciplinamiento en la formación por medio del control, la clasificación o el castigo, tema frente al cual los autores se muestran consecuentes y construyen bifurcaciones pedagógico-filosóficas que contradicen las formas de castigo en la formación escolar (Nietzsche, 2009; Freire 1980, 2015); en seguida, liberación de las teorías y las prácticas ligadas a la domesticación, sobre todo en la formación escolar (que termina siendo parte funcional de una educación política, moral y religiosa de los sujetos, pero que gira en torno a elementos acríticos). Si no hubo mejoramiento por medio del disciplinamiento de los cuerpos, no puede haberlo por medio del sometimiento de las mentes.

La educación no puede, entonces, deslindarse de la finitud del sustrato filosófico, es decir, del amor por el pensar, del amor por enseñar (Freire, 2015, p. 132; Zuleta, 2016, p. 45) o en otras palabras, la libertad humana como la posible potencia de la rebeldía ${ }^{1}$. El posible impulso de la educación se sostiene en la transmisión de sentimientos y conocimientos y en el flujo de la misteriosa re-

\footnotetext{
1. Quizás no sea del todo concreto indicar que esta sugerencia a la rebeldía provenga de una posible raíz marxista dentro del pensamiento freireano. Es evidente que en Freire no se logra entender la idea de libertad en el mismo sentido como lo presupone el marxismo, sino más bien en relación a un ecumenismo religioso del cual Freire hace alusión en varios textos y entrevistas (Freire, 2015; Freire y Faundez, 2018). Habría que mencionar que si bien el mismo Freire admite haber escrito su célebre Pedagogía del oprimido bajo el método de Marx del análisis de clase, esta fue una situación que la misma comunidad marxista de su tiempo le reprochó. En palabras del propio Freire: "no deja de ser irónico que algunos marxistas me hayan criticado por no haber prestado suficiente atención al análisis de clase social” (Freire, 2015, p. 143).
} 
beldía que implica la posibilidad de lo ininteligible que caracteriza a la libertad humana (Nietzsche, 2009, pp. 142-149; Freire, 2015, pp. 129-138).

Las formas de saber que designan al ser humano, la naturaleza, la sociedad, al Otro, no tienen que componerse de dogmatismos. En ese sentido en la concepción de educación se tiene que comprender que "no hay ningún concepto universal de saber, como tampoco hay una esencia universal de las cosas", hay distintas formas de saber y distintas formas de adquirir saber (Feyerabend, 2015), asimismo que el concepto de realidad influye en el modo de pensar, actuar y sentir de los seres humanos, y que ese concepto es construido a partir de distintos factores psicológicos, sociales y culturales (Feyerabend, 2015, p. 128); por eso, puede resultar inadmisible que la educación vea en el escenario del mercado o en la tecnologización su realidad absoluta. La vida humana se caracteriza por sus distintas formas de realidad, es decir, por su estadio hasta el momento indefinible de alteridad.

Por otra parte, la libertad indicada por el neoliberalismo actual que parte del capitalismo cognitivo y financiero no tiene que confundirse con un liberalismo intempestivo de Dewey, Tocqueville o Arendt, por ejemplo. Lo que se define en pleno arranque del siglo XXI como "libertad" para el neoliberalismo se entiende como la asimilación de las doctrinas del libre mercado donde lo público supone una subvención directa al sector financiero y empresarial (Chomsky, 2016).

En este punto, se debe comprender que las ideas tradicionales que encarnan lo político, lo económico, lo cultural, solamente adquieren su movimiento si existe una operatividad mantenida en la lógica de la compra y venta del Otro y del Mundo (Chomsky, 2001). Y esta situación parece pronunciar también el gran error de la creciente militarización, la falsa democratización y la ridícula redistribución de la riqueza de la mayoría de los gobiernos actuales, especialmente en Latinoamérica. En educación, engrandecer los encantos del mercado, antes que emprender una crítica filosófica y cultural sobre esta situación, también es parte del error.

En síntesis, para estos tres autores la educación y su relación con la libertad humana implica la permanente apertura hacia la actitud crítica, la construcción-transformación y el arranque ético-político hacia otras relaciones humanas con los saberes y los valores (Nietzsche); persistir en la lucha contra todo tipo de opresión y contra la invisibilización de la alternatividad (Freire); encontrar en la educación filosófica, desde el reconocimiento del Otro y el desarrollo de pensamiento crítico, una posible fuente para lograr la afirmación de la vida (Zuleta). 


\section{Conclusiones}

La filosofía nietzscheana también se ocupa de la educación del ser humano, no aspira a ser una filosofía universal; por tanto, si es que existen resultados de su interpretación éstos tienen que sospecharse por fuera de la dominación y la hegemonía.

La pedagogía freireana establece relaciones entre la educación y las necesidades sociales, pero desde una perspectiva que encuentra desafortunada la inmersión de la educación en el terreno del neoliberalismo (lógica del mercado, teorías eurocéntricas, modelos predeterminados, proyecto de domesticación).

La educación filosófica resulta para Zuleta una posible respuesta ante el problema de una formación escolar acrítica y que inhibe el pensamiento o prepara sujetos para su domesticación y adoctrinamiento.

La libertad en educación, entonces, es saber con el fin de disentir, elegir, co-crear junto al Otro para que se logre un modo de ser y estar más inquietante que permita sentir o desprender pensamiento sobre la sociedad, para entender entre quiénes se convive para comprender qué información, métodos, relatos se consumen, aceptan y transgreden, para así aprender a criticarlos y a criticarse, quizás apuntando hacia otra ética y hacia otras formas de pensar.

\section{Referencias}

Castro-Gómez, S. (2016). Crítica a la razón latinoamericana. Bogotá, Colombia: Universidad Javeriana.

Chomsky, N. (2001). La (Des)Educación. Barcelona, España: Crítica.

Chomsky, N. (2016). El beneficio es lo que cuenta. Neoliberalismo y orden global. Madrid, España: Austral.

Colli, G; Montinari, M. (2004). Nietzsche. Fragmentos póstumos. Madrid, España: Abada.

Colli, G; Montinari, M. (2008). Nietzsche. Fragmentos póstumos. Madrid, España: Tecnos. 
Condorcet, N. (1993). La ilustración olvidada. Madrid, España: Anthropos

Deleuze, G. (2008). La filosofía crítica de Kant. Madrid, España: Cátedra.

Deleuze, G. (2013). Nietzsche y la filosofía. Barcelona, España: Anagrama.

Feyerabend, P. (2015). Filosofía natural. Bogotá, Colombia: Penguin Random House.

Foucault, M. (2008). La hermenéutica del sujeto. Buenos Aires, Argentina: FCE.

Freire, P. (1980). Pedagogía del oprimido. Bogotá, Colombia: Siglo XXI.

Freire, P. (2002). La educación como práctica de libertad. Madrid, España: Siglo XXI.

Freire, P. (2015). Pedagogía de los sueños posibles. Buenos Aires, Argentina: Siglo XXI.

Freire, P.; Faundez, A. (2018). Por una pedagogía de la pregunta. Buenos Aires, Argentina: Siglo XXI.

Gadamer, H. (1997). Mito y razón. Barcelona, España: Paidós.

Galcerán, M. (2007). Reflexiones sobre la reforma de la Universidad en el capitalismo cognitivo. Revista Nómadas, 27, 86-97. http://biblioteca.clacso. edu.ar/ar/libros/colombia/iesco/nomadas/27/8_galceran_huguet.pdf [Consultado el 13 de noviembre de 2018].

Han, B. (2015). Psicopolítica. Madrid, España: Herder.

Heidegger, M. (2013). Nietzsche. Madrid, España: Ariel.

Jaspers, K. (2003). Nietzsche. Introducción a la comprensión de su filosofía. Buenos Aires, Argentina: Sudamericana.

Kant, I. (2015). ¿Qué es la ilustración? Medellín, Colombia: Universidad de Antioquia. 
Kincheloe, J. (2001). Hacia una revisión crítica del pensamiento docente. Barcelona, España: Octaedro.

Mignolo, W. (2017). El lado más oscuro del renacimiento. Alfabetización, territorialidad y colonización. Popayán, Colombia: Universidad del Cauca.

Nietzsche, F. (2000). Sobre el provenir de nuestras escuelas. Barcelona, España: Tusquets.

Nietzsche, F. (2003). Ecce Homo. Madrid, España: Edimat.

Nietzsche, F. (2009). Aurora. Reflexiones sobre los prejuicios morales. Barcelona, España: Random House Mondadori.

Onfray, M. (2002). Cinismos. Buenos Aires, Argentina: Paidós.

Rousseau, J. J. (1999). Emilio o de la educación. Medellín, Colombia: Cometa Editores.

Santos, B. (2014). Descolonizar el saber. Reinventar el poder. Santiago, Chile: LOM.

Schopenhauer, A. (2002). Los dos problemas fundamentales de la ética. Barcelona, España: Siglo veintiuno.

Siemens, H. (2014). Haciendo la guerra a la guerra: Nietzsche contra Kant, a propósito del conflicto. Pléyade, 13, 87-106. https://biblat.unam.mx/ hevila/PleyadeSantiago/2014/no13/5.pdf [Consultado el 13 de noviembre de 2018].

Wallerstein, I. (2005). La decadencia del poder estadounidense. México D. F.: México: Era.

Zuleta, E. (2016). Educación y democracia. Bogotá, Colombia: Ariel.

Zuleta, E. (2018). Elogio de la dificultad y otros ensayos. Bogotá, Colombia: Ariel. 
